\title{
Studying the Problems of Attracting Attention in the Physical Education Lesson for the Preparatory Stasge from the Female Teachers Point of View
}

\author{
Jihan Karim Amana ${ }^{1}$, Mohssen Ali Musa ${ }^{2}$ \\ ${ }^{1}$ M.Sc., Student, ${ }^{2}$ Prof. Dr., College of Physical Education and Sports Science
}

\begin{abstract}
The lesson of physical education is more vulnerable to the problems of attracting attention as it is in a wider area and includes freedom of movement and flexibility in dealing in the classroom and sometimes the distraction in the physical education school increases due to the large number of female students, thus providing the opportunity to practice such behavioral problems, since the practice of sports activity, especially the physical education lesson, is appropriate for free behavior and from it turns into an abnormal behavior as a result of being affected by the family circumstances to which the female students belong, Hence the importance of this research shows that the problems of attracting attention If the professors, educators, and researchers do not work with research to determine it, which leads to female students' personal and social maladjustment in and outside the school, then when these problems are left without supervision, it may lead to their increase and the difficulty of dealing with them, In addition to the inability of female students to agree in the school, and therefore, a barrier between them and benefiting from the school's educational and educational services that achieve integrated and balanced growth for all aspects of personality, to qualify them for the right citizenship in line with the goals of society, As for the research methodology, the researcher used the descriptive approach in the survey method to suit the nature of the research problem. As for the research sample, the research community was identified as physical education female teachers in Dhi Qar Governorate for the preparatory stage as shown in table (1) so the number of schools reached (50) schools, while the number Female teachers reached (235) Female teachers. As for the research findings, the most important of them is the scale that was prepared by researchers as a tool to uncover problems of attracting attention in the lesson of physical education for the preparatory stage from the point of view of female teachers. They resort to attract the attention of others With negative behavior.
\end{abstract}

Keywords: problems, physical education lesson, preparatory stage, female teachers

\section{Introduction}

The lesson of physical education is more vulnerable to the problems of attracting attention as it is in a wider area and includes freedom of movement and flexibility in dealing in the classroom and sometimes the distraction in the physical education school increases due to the large number of female students ${ }^{1}$, thus providing the opportunity to practice such behavioral problems, since the practice of sports activity, especially the physical education lesson, is appropriate for free behavior and from it turns into an abnormal behavior as a result of being affected by the family circumstances to which the female students belong, And their social and cultural level and the lesson of physical education ${ }^{2}$, therefore, attention to behavioral problems is one of the important pillars of education and its importance comes from the fact that education means a change in the behavior of female students towards the best under the influence of conditions, experiences, knowledge and skills that students pass in educational and educational situations, so the impact of education and education is evident In the positive behavior of female students ${ }^{3}$, as what appeared to be unwanted behavior among female students was worthy of study and research, Hence the importance of this research shows that the problems of attracting attention If the professors, educators, and researchers do not work with research to determine it, 
${ }^{4}$ which leads to female students' personal and social maladjustment in and outside the school, then when these problems are left without supervision, it may lead to their increase and the difficulty of dealing with them, In addition to the inability of female students to agree in the school, and therefore, a barrier between them and benefiting from the school's educational and educational services that achieve integrated and balanced growth for all aspects of personality, to qualify them for the right citizenship in line with the goals of society ${ }^{5}$. Therefore, the two researchers decided to go into this study to find out the reasons that contributed to the existence of these behavioral problems and identify them as a contribution from us in determining these behaviors in an accurate scientific way through building and applying ${ }^{6}$ a scale of attention-grabbing problems in the lesson of physical education for the preparatory stage from the viewpoint of female teachers in Dhi Qar Governorate .

\section{Research methodology and field procedures:}

\section{Research methodology}

The researchers used the descriptive approach in the survey method to suit the nature of the research problem. "Descriptive research" aims to determine the conditions and relationships that exist between the facts and appearances and the survey method seeks to collect data from community members to try to determine the current state of society in a particular variable or two variables.

\section{Populations and research sample}

The research community was identified as physical education teachers in Dhi Qar Governorate for the preparatory stage, as shown in Table (1), as the number of schools reached (50) schools, while the number of female teachers reached (235)

Table (1) Number of female teachers, surveying personnel, and construction and implementation samples

\begin{tabular}{|c|c|c|c|c|c|c|c|c|}
\hline & Administrative Unit & Populations & $\begin{array}{l}\text { Study } \\
\text { sample }\end{array}$ & ratio & $\begin{array}{l}\text { Construction } \\
\text { sample }\end{array}$ & ratio & $\begin{array}{l}\text { implementation } \\
\text { samples }\end{array}$ & ratio \\
\hline 1 & Nasiriyah & 50 & 2 & \multirow{9}{*}{$4.25 \%$} & 36 & \multirow{9}{*}{$67.5 \%$} & 12 & \multirow{9}{*}{$45 \%$} \\
\hline 2 & Shatra & 43 & 1 & & 30 & & 12 & \\
\hline 3 & Gra'af & 40 & 1 & & 21 & & 18 & \\
\hline 4 & Batha'a & 20 & 2 & & 13 & & 5 & \\
\hline 5 & Souq Al-Shouokh & 35 & - & & 18 & & 17 & \\
\hline 6 & Al-Fadhliyah & 12 & 1 & & 4 & & 7 & \\
\hline 7 & Al-Islah & 15 & 3 & & 7 & & 5 & \\
\hline 8 & Syed Dakhil & 20 & - & & 6 & & 14 & \\
\hline 9 & Total & 235 & 10 & & 135 & & 90 & \\
\hline
\end{tabular}

\section{Devices that used in the research}

- $\quad$ Laptop (Acer)

- Manual calculator (kenko)

\section{Tools that used in the research}

- Arabic and foreign sources and references. 
- International Information Network (Internet) .

- Auxiliary Work Team.

- Pens and pencils.

\section{Main research procedures}

The researchers prepared a questionnaire to measure the problems of attracting attention in the lesson of physical education for the preparatory stage (for female students) from the viewpoint of female teachers of physical education in a manner appropriate to the scientific foundations from which the subject of its research was launched.

\section{Final implementation for scale}

The researchers applied a questionnaire to measure attention problems in the physical education lesson on a sample consisting of (90) female teachers of physical education from the research community, and this sample is called (sample application scale) and their percentage reached about (45\%) of the parent community, and that was on the corresponding Tuesday 20/2/202.

\section{Presentation, analysis and discussion of results}

Display the results of the mea arithmetic mean and standard deviation and the value of the hypothetical mean and the lowest and largest value of answers to the field of Attract attention to the implementation sample and discuss it.

\begin{tabular}{|l|l|l|l|l|l|l|l|l|}
\hline Field & Sample & $\begin{array}{l}\text { Arithmetic } \\
\text { mean }\end{array}$ & $\begin{array}{l}\text { Standard } \\
\text { deviation }\end{array}$ & $\begin{array}{l}\text { hypothetical } \\
\text { mean }\end{array}$ & $\begin{array}{l}\text { Lowest } \\
\text { value }\end{array}$ & $\begin{array}{l}\text { largest } \\
\text { value }\end{array}$ & $\begin{array}{l}\text { (t) } \\
\text { Value }\end{array}$ & $\begin{array}{l}\text { Significance } \\
\text { level }\end{array}$ \\
\hline $\begin{array}{l}\text { Attract } \\
\text { attention } \\
\text { problems }\end{array}$ & 90 & 90.544 & 10.798 & 90.544 & 88.282 & 92.806 & 79.545 & 0.000 \\
result
\end{tabular}

Table (2) Arithmetic mean and standard deviation and the value of the hypothetical mean and the lowest and largest value of answers to the field of Attract attention

In light of the results extracted for the individuals of the research sample in Table (14), it shows the value of the arithmetic mean for the field of attention-attracting problems $(90,544)$ and with a standard deviation (10.798) and the hypothetical mean value was $(90,544)$ while the calculated value of $\mathrm{T}$ was $(79,545)$ at the level of significance $(0,000)$ less than $(0.05)$.

This indicates that female students have the desire and need for physical education teachers or their colleagues to accept them and have a special status, through their attempt to attract their forced attention, but some of them fail to achieve this with desired behavior in it, and perhaps we find that female students use verbal or other behavior Verbal to attract the attention of the rest of the students or the school of physical education leaving the motor duties assigned to them and this of course greatly affects the educational and educational goals, so when the student finds an overwhelming pleasure to come up with some movements and behaviors that everyone laughs inevitably, this behavior will affect the time of hers Unless there are efforts made to prevent them to curb such behavior and drive the wheel in the direction previously planned, which made them search for praise and praise with unacceptable behaviors.

Indeed, female students who are unable to achieve standing among others in a socially acceptable way resort to using unacceptable behavioral patterns to attract attention in order to achieve basic personal goals, perhaps the most important of which is related to achieving social status for students among their peers, which enhances their social identity, and gives them the opportunity to impose control, and gain Power and influence, and hence challenge existing power and ultimate immersion in love for adventures.

The researcher stresses that the problems of attracting attention (the search for status) are the main behavioral problems after the aggressive behavior 
faced by physical education teachers during the lesson educational institutions with the accompanying methods of silver or material to disturb the system within the lesson, which in turn affects the concept of physical education and its status as an educational system has His goals which seek to improve the general human performance through the chosen sporting activities as an educational mediator characterized by educational and educational characteristics in preparing students for a comprehensive and integrated preparation to be good citizens who benefit themselves and their country.

The researcher believes that such behavior is predominant in the nature of psychological disorder, whose phenomena are kinetic or silvery of an abnormal, it appears that it arises from the imbalance between the tendencies and impulses of students and the adjustment system, and when the adjustment is inappropriate, they resort to compensation in another field for their academic failure, and this What "Suhair Ahmed 2001" referred to by saying: Compensation is the individual's tendency towards another behavior as compensation for behavior that he has failed and failed in order to reduce the tension resulting from the severity of frustration that he is exposed to. Therefore, the behavior of female students becomes aggressive, dispersed and unpredictable, and when the adjustment is very strict, the student tries to stop her behavior continuously and is unable to express herself, therefore, the intervention tactics help female students to develop appropriate control of their tendencies, and the researcher adds that such Such behaviors do not happen by chance or by force, but are the results of past experiences.

\section{Inferences and recommendations}

In light of the research results and the statistical analysis of data obtained from the behavioral problems scale in the physical education lesson, the researcher reached the following inferences :

- The scale that has been prepared by researchers is a tool for detecting attention-grabbing problems in a physical education lesson for middle school from the teachers' point of view.

- Middle school students at age experience difficulties in proving themselves, so they resort to attracting the attention of others through negative behavior.

- Middle school students seek to compensate for their feelings of dissatisfaction with themselves, a lack of some aspect of their personality, or a lack of self-confidence motivating them to work to attract attention.

- The preparatory stage students do not have the ability to coordinate between the satisfaction of their needs and the requirements of the school environment, forcing them to lead to improper behavior.

\section{Recommendations}

Use the research tool to measure the problems of attracting attention to the preparatory stage for students to identify the problems that teachers face in implementing physical education lesson activities.

- Overcoming the difficulties and behavioral problems, such as the problems of attracting attention that face prep students, by holding workshops or training courses for psychological counseling.

- Study factors affecting behavioral problems such as methods of socialization, cultural, economic and social level of the family and other factors.

- Using the proposed methods to address behavioral problems in the physical education lesson for primary school students and middle school students.

Financial Disclosure: There is no financial disclosure.

Conflict of Interest: None to declare.

Ethical Clearance: All experimental protocols were approved and all experiments were carried out in accordance with approved guidelines.

\section{References}

1. Aaron B. Cognitive Therapy and Emotional Disorders, (translation by Adel Mustafa), Beirut, Dar Al-Nahdha for Printing and Publishing, 2000; 188. 
2. Asma AA. Psychological behavioral problems in children (their causes - methods of overcoming them), 2nd Edition, Al-Rushd Library, Riyadh, 2004; 21.

3. Amina A, Adel M. The Fourth American International Diagnostic and Statistical Manual of Mental Disorders, 2nd Edition, Al-Manar Islamic Library, Kuwait, 2001; 67.

4. Now C. Behavioral disorders for children and adolescents, (translated by Adel Abdullah), Dar Al Rashad, Cairo, 2000; 52.

5. Iman SS. Behavioral problems and their relationship to academic preparation among a sample of middle school students in Al-Khobar Governorate, Master
Thesis, King Abdulaziz University, Saudi Arabia, 2013.

6. Bashir A. Classroom Management and Learning Environment Regulation, 1st Edition, Dar Al Thaqafa for Publishing and Distribution, Jordan, 2007; 193.

7. Issam A. Levels of Tendency to Violence and Aggressive Behavior among Students, Journal of Educational Sciences, 2001; 2: 501.

8. Soheir AK. Child Mental Health, Alexandria Book Center, Egypt, 2001; 89. 